\title{
Breast Cancer: The Accuracy of The Paus in Detecting pN2 and Factors that Lead to the True- and False-Negative Results
}

\author{
Dalia Artmoniene*1, Algirdas Bogusevicius ${ }^{2}$, Egle Jonaitiene ${ }^{2}$, Renata Paukstaitiene ${ }^{3}$, Vincentas Veikutis ${ }^{3}$, Milda \\ Baseviciute $^{3}$ and Karolina Stasiukynaite ${ }^{3}$ \\ ${ }^{1}$ Lithuanian University of Health Sciences, Lithuania
}

${ }^{2}$ The Hospital of Lithuanian University of Health Sciences (LSMU) Kauno klinikos, Lithuania

${ }^{3}$ Lithuanian University of Health Sciences, Lithuania

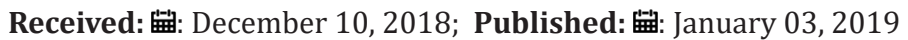

*Corresponding author: Dalia Artmoniene, Lithuanian University of Health Sciences, Lithuania

\begin{abstract}
About 70\% of early breast cancer cases axillary lymph nodes are intact and surgical axillary intervention is unnecessary. There is an ongoing search for non-invasive methods to evaluate the status of axillary lymph nodes in order to prevent Axillary Lymph Node Dissection (ALND) or Sentinel Lymph Node Biopsy (SLNB). Patients with normal axillary physical exam and ultrasound rarely harbor a large nodal disease burden (pN2). There are studies suggesting that the Preoperative Axillary Ultrasound (PAUS) can replace SLNB when the axillary surgery is no longer curative and only biomarkers are important for adjuvant chemotherapy. The purpose of this study was to determine the accuracy and reliability of the ultrasound examination in detecting more than three metastatic axillary lymph nodes (pN2) and to assess the clinicopathological factors that lead to the truenegative and false-negative results of the ultrasound study. All patients underwent the PAUS as part of their staging. The nodal status assessed by PAUS was compared with histological findings. Determining pN2, the accuracy of PAUS was $91.2 \%$ and the NPV - $96.5 \%$. False-negative results of PAUS were $18.7 \%$. On bivariate analysis, primary Tumor Size (T), the tumor spreading in blood and Lymphatic Vessels (LV), Tumor Grade (G) and patient age were found to be significantly different between true- and false-negative PAUS. We found that PAUS is sufficiently accurate to detect a heavy nodal disease burden and in most cases an additional axillary surgery can be avoided. PAUS findings may be less accurate in young age and in patients with T2, G3 and LV1.
\end{abstract}

Keywords: Breast Cancer; Axillary Lymph Node; Ultrasound

Abbreviations: PAUS: Preoperative Axillary Ultrasound; ALND: Axillary Lymph Node Dissection; SLNB: Sentinel Lymph Node Biopsy; pN2: $>3$ Metastatic Lymph Nodes; NPV: Negative Prognostic Value; T: Tumor Size; LV1: Tumor Spreading in blood and Lymphatic Vessels; G: Tumor Grade

\section{Introduction}

The condition of Axillary Lymph Nodes (ALN) is the most important prognostic factor in breast cancer and is relevant to the choice of breast cancer treatment tactics [1,2]. There is a strong correlation between the number of damaged axillary lymph nodes and the risk of breast cancer regeneration [3]. Since 1994, Sentinel Lymph Node Biopsy (SLNB) has become a gold standard for assessing the status of the axillary lymph nodes. The sentinel lymph node is hypothetically the lymph node or group of lymph nodes that the primary cancer cells reach first. If the sentinel lymph node is intact, the probability that the tumor will not spread is high. According to several studies, when metastases are detected and the secondary
Axillary Lymph Nodes Dissection (ALND) is performed, in 40-70\% of cases, additionally removed lymph nodes were healthy [4]. When isolated tumor cells or micrometastases are found after SLNB, the removal of other lymph nodes in the axilla is not recommended [5]. A randomized ACOSOG Z0011 study was presented at the annual conference of the American Society of Oncology (ASCO) in 2010, which found that survival and the risk of recurrence was very similar in patients with T1 or T2 tumors and during SLNB 1 or 2 damaged lymph nodes who had ALND and those who did not [5].

About $70 \%$ of the early breast cancer cases have intact axillary lymph nodes and surgical axillary intervention is unneces- 
sary [6]. Although SLNB complications are rare and less damaged than ALND, this is a risky procedure. Several prospective studies (ACOSOG Z0010, NSABP B-32, ALMANAC) identified the incidence and frequency of SLNB complications: allergic reactions (0.1-1.0\%), wound infection (1.0-10\%), seroma (7.1\%), paresthesia (8.6-11\%) and hematoma (1.4\%) [7]. Accordingly, there is an ongoing search for non-invasive methods to evaluate the status of axillary lymph nodes in order to prevent ALND or SLNB [6]. In the guidelines of the European Union, Preoperative Axillary Ultrasound (PAUS) is a routine examination for all breast cancer patients with palpable or impalpable axillary lymph nodes [4]. It is possible to assess whether the lymph node is damaged by ultrasound (PAUS-positive) according to the morphological features of the axillary lymph node [7]. In different studies, the sensitivity and accuracy of the ultrasound examination varied between $23 \%$ to $87 \%$ and $67.9 \%$ to $90.2 \%$ $[2,5,6-18]$. One of the weaknesses in the ultrasound examination is the false-negative results $(\sim 21 \%)$ [15], but in the determination of metastases in three or more axillary lymph nodes, false negative tests are found to account for about 4\% [2].

Symptoms of the disease are less favorable and the prognosis is poorer in patients who are PAUS- positive [4] versus patients who are PAUS negative and metastases were found rarely in more than three axillary lymph nodes [2]. There are studies suggesting that an ultrasound examination can replace SLNB when the axillary surgery is no longer curative and only biomarkers are important for adjuvant chemotherapy [7]. The purpose of this study was to determine the accuracy and reliability of the ultrasound examination in detecting more than three metastatic axillary lymph nodes (pN2) and to assess the clinicopathological factors that lead to the true-negative and false-negative results of the ultrasound study.

\section{Materials and Methods}

The present study is a retrospective analysis of the medical documentation of all newly diagnosed breast cancer patients between 1 January 2011 and 31 December 2012 in the Hospital of Lithuanian University of Health Sciences Kauno klinikos. The study included women ( $n=667)$ who underwent a preoperative axillary ultrasound examination. When normal-appearing or suspicious axillary lymph nodes were found during the ultrasound study, SLNB was performed. If there were definitely pathological axillary lymph nodes by ultrasound examination, an immediate ALND was performed or treatment started with neoadjuvant chemotherapy (these women were not included in the study). The criteria for assessing the lymph nodes are shown in Table 1 . The cases of breast cancer found on both breasts were analyzed as two separate cases. Rejection criteria: Neoadjuvant chemotherapy, recurrent breast cancer, non-invasive breast cancer, unexplored or poorly documented PAUS study. PAUS study data were compared to the results of postoperative histological examination. The study design is shown in Figure 1). PAUS was performed using an Acuson S2000 ultrasound unit with a $14 \mathrm{MHz}$ linear Siemens transducer.

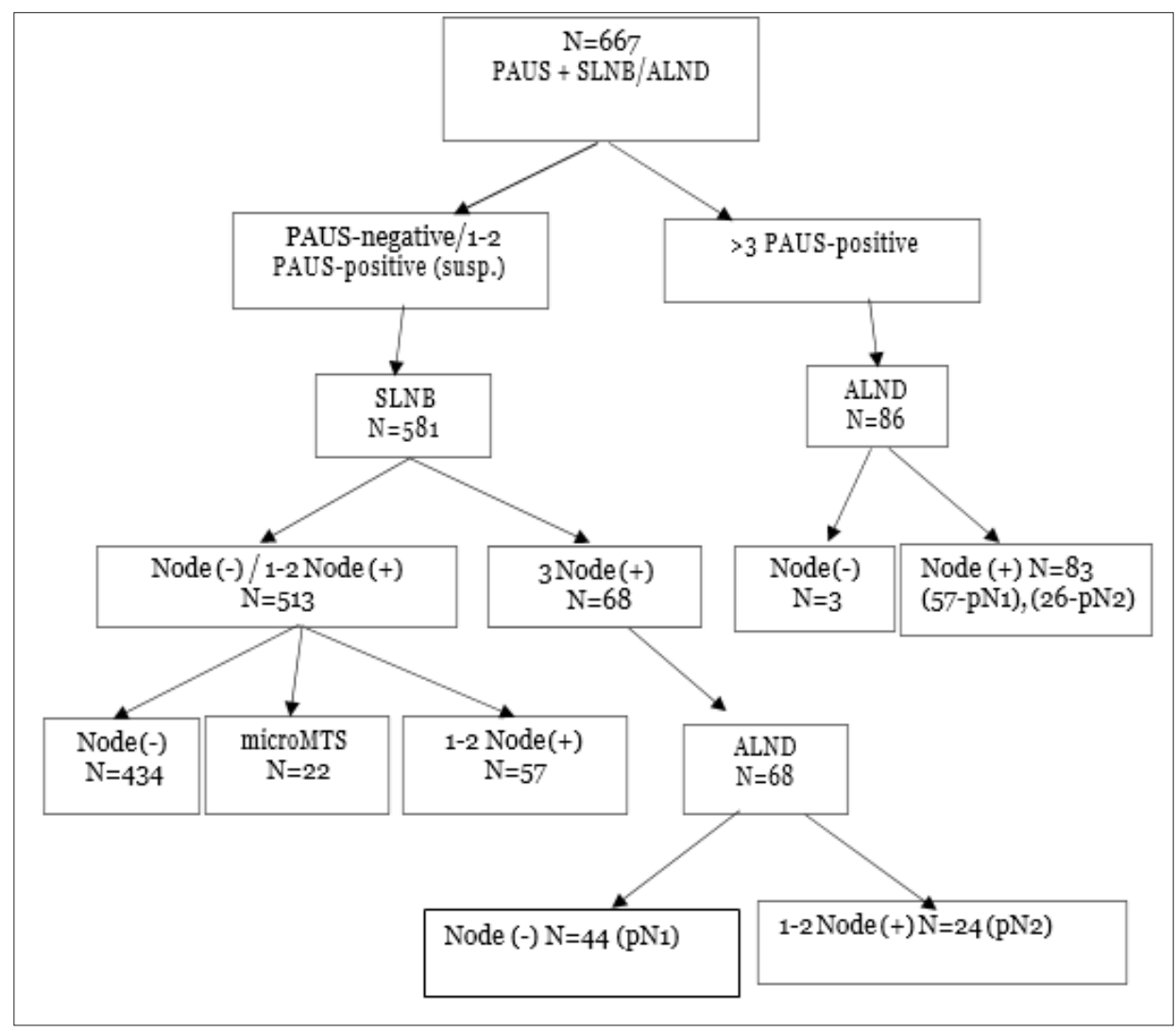

Figure 1: Study design - axillary assessment protocol. 
Table 1: PAUS lymph node evaluation criteria.

\begin{tabular}{|c|c|c|c|}
\hline Lymph Node Status Sign & $\begin{array}{c}\text { Normal-Appearing (PAUS-Neg- } \\
\text { ative) }\end{array}$ & Suspitious (PAUS-Positive) Susp. & Pathological (PAUS-Positive) \\
\hline Shape & Oval & Oval/rounded & Rounded \\
\hline Cortex & $<=3 \mathrm{Smm}$ & Diffusion/local thickening $>3 \mathrm{~mm}$ & Does not differentiate \\
\hline Gate & Unchanged, crearly visible & Dislocated & Does not differentiate \\
\hline Vascularity & Central & Mixed/peripheral & Intense in all lymph node \\
\hline
\end{tabular}

The sentinel lymph nodes were marked by injection periareolarly of $0.2 \mathrm{ml}-50 \mathrm{MBq}$ of $99 \mathrm{mTC}$ - labeled nanocole one day before surgery. The location of the sentinel lymph node was detected using the 2010 Philips BrightView Gamma Camera and detected during the operation with the Crystal Probe-automatic-handheld gamma detector. Surgically removed radioactive lymph nodes were sent for pathological examination (hematoxylin and eosin staining and immunohistochemistry). PAUS data were compared with histological examination results. The following histopathological data were analyzed: Tumor Size (T), Tumor Grade (G), Lymphovascular Invasion (LV), the presence of Estrogen (ER) or Progesterone (PR) receptors, Human Epidermal Growth Factor (HER2) status and Lymph Nodes $(\mathrm{pN})$ status.

\section{Statistical Analyses}

Statistical analysis was performed using IBM SPSS Statistics 24 package. Descriptive statistics methods were used to systemize the research data. The accuracy, sensitivity, specificity, Positive Predictive Value (PPV) and Negative Predictive Value (NPV) of the ultrasound examination were evaluated and the estimates of these characteristics were given along with their 95\% confidence intervals. The Chi-square test was used to compare effects of clinicopathological factors and the correlation of outcomes from PAUS and SLNB pathology. The results were considered statistically significant if $\mathrm{p}<0.05$.

\section{Results}

The study analyzed 667 females aged from 27 to 88 years old, with an average age of 60.07 (SD=12.451). By age, patients were divided into three groups: young $(<40$ years, $n=30(4.5 \%))$, middle age (40-69 years, $n=476(71.4 \%)$ ) and elderly ( $\geq 70$ years, $n=161$ (24.1\%)). Patient demographic and tumor clinopathological data are presented in Table 2 . Small tumors were found more frequently (T1 - 52.2\%). The majority of tumors were moderately- differentiated (G2), in $63.7 \%$ of cases. Tumor spreading in blood vessels and lymphatic vessels was found in $36.2 \%$ and $49.6 \%$ of cases. More frequently, ER (+) (43.3\%), PR (-) (44.7\%) and HER2 (-) (57.0\%) tumors were detected (Table 2). By PAUS, pathological lymph nodes were found in 86 cases and lymphodectomy was performed; for all remaining cases $(\mathrm{N}=581)$, SLNB was performed. Metastatic lymph nodes (node-positive) were diagnosed in 230 cases (34.5\%) (pN1 $28.4 \%$, pN2 - 6.1\%), and the axillary lymph nodes were undamaged (node-negative) (pN0) in 437 cases (65.5\%). After SLB, metastases were detected in three sentinel lymph nodes in 68 cases $(11.7 \%)$ and secondary ALND was performed. Of all of the additional removed lymph nodes, metastases were found in one or two lymph nodes (pN2) in 24 (35.3\%) cases, while the additional removed nodes were undamaged in the remaining 44 cases (64.7\%). Therefore, of the 581 SLB, heavy nodal disease burden (pN2) was only found in 24 cases $(4.1 \%)$ (Figure 1$)$.

Table 2: PAUS true-false-negative and true-false-positive results according to patient and tumor characteristics.

\begin{tabular}{|c|c|c|c|c|c|c|c|}
\hline \multirow{2}{*}{\multicolumn{2}{|c|}{ Characteristic }} & \multicolumn{5}{|c|}{ Number of Patients $(\mathrm{N}=667)$} & \multirow{2}{*}{ P-Value } \\
\hline & & Total & True- Negative & False- Negative & True- Positive & False- Positive & \\
\hline \multirow{3}{*}{ Age } & $<40$ & $\begin{array}{r}30 \\
(4.5 \%)\end{array}$ & $\begin{array}{c}11 \\
(2.7 \%)\end{array}$ & $\begin{array}{c}13 \\
(10.4 \%)\end{array}$ & $\begin{array}{c}5 \\
(4.8 \%)\end{array}$ & $\begin{array}{c}1 \\
(3.7 \%)\end{array}$ & \multirow{3}{*}{0.006} \\
\hline & $40-69$ & $\begin{array}{r}476 \\
(71.4 \%)\end{array}$ & $\begin{array}{l}302 \\
(73.7 \%)\end{array}$ & $\begin{array}{l}86 \\
(68.8 \%)\end{array}$ & $\begin{array}{l}73 \\
(69.5 \%)\end{array}$ & $\begin{array}{l}15 \\
(55.6 \%)\end{array}$ & \\
\hline & $>=70$ & $\begin{array}{r}161 \\
(24.1 \%)\end{array}$ & $\begin{array}{l}97 \\
(23.7 \%)\end{array}$ & $\begin{array}{l}26 \\
(20.8 \%)\end{array}$ & $\begin{array}{l}27 \\
(25.7 \%)\end{array}$ & $\begin{array}{l}11 \\
(40.7 \%)\end{array}$ & \\
\hline
\end{tabular}

PAUS-negative axillary lymph nodes were found in 535 cases, of which heavy nodal disease burden (pN2) was detected in only 15 cases $(2.8 \%)$. PAUS-positive axillary lymph nodes were evaluated in 132 cases: 86 as pathological ( 3 cases were node-negative, 83 cases were node-positive), and 46 as suspicious ( 24 cases were node-negative, 22 cases were node-positive) (Figure 2). In general, PAUS was not very sensitive $(45.7 \%)$ but was very specific (93.8\%), sufficiently accurate $(77.2 \%)$ and had rather high posi- tive and negative predictive values (79.5\% and 76.6\%). According to age groups, metastases were most commonly found in young women (60\%), but the accuracy of PAUS was the lowest (53.3\%); in middle and older women, metastases in the axillary lymph nodes were found less frequently (33.4\% and $32.9 \%$ ) and the PAUS was quite accurate $(78.8 \%$ and $77.0 \%)$. Determining more than three metastatic lymph nodes (pN2), the accuracy of PAUS was $91.2 \%$ (95\% confidence interval $[\mathrm{CI}]=88.7-93.8)$, sensitivity was $63.4 \%$ 
(95\% CI=48.7- 78.2) and NPV was 96.5\% (95\% CI=94.7-98.2) (Table 3). Of the 535 patients who were PAUS-negative, metastases were detected in 125 cases (18.7\%) in the histological examination (false-negative results).

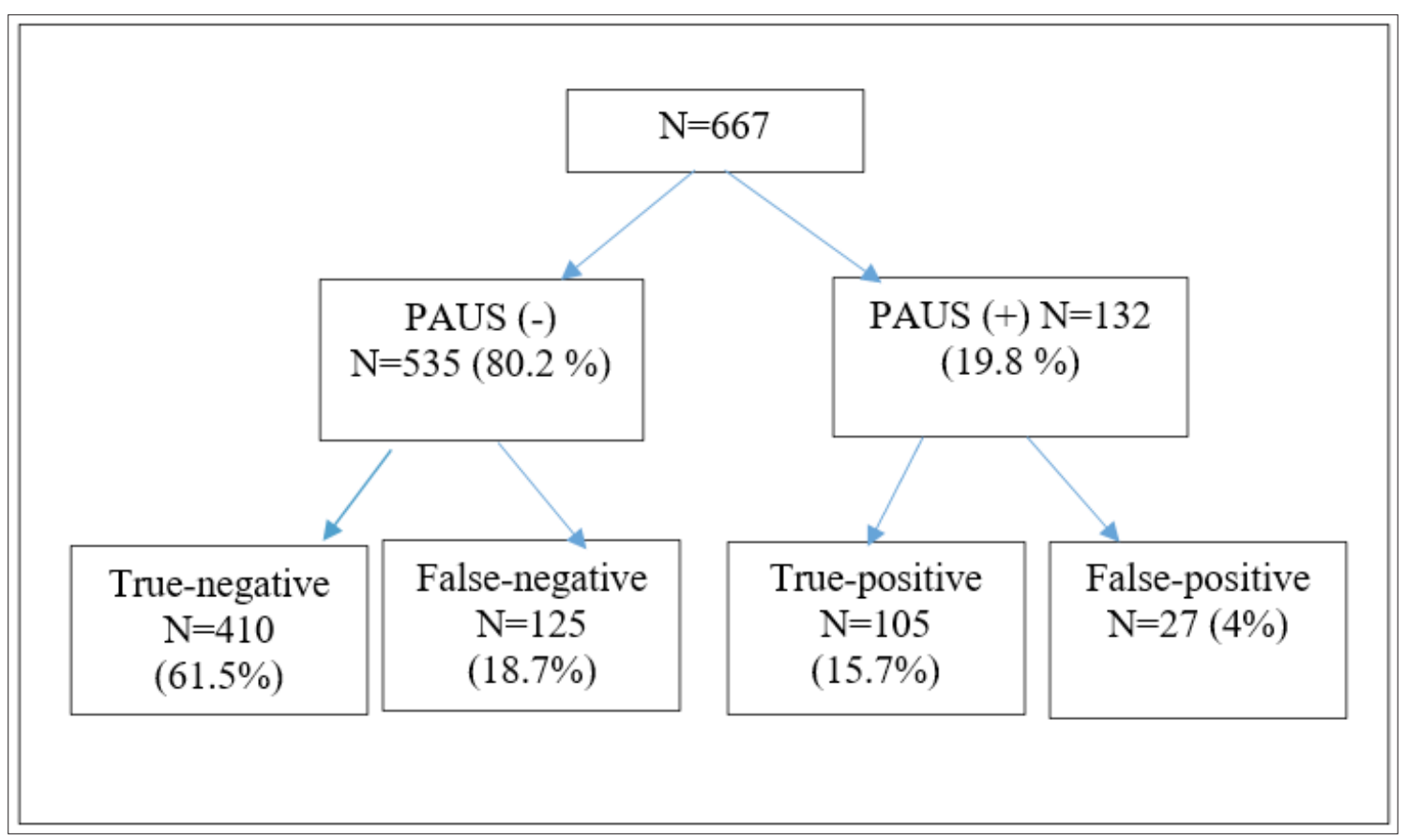

Figure 2: PAUS and pathological results scheme.

Table 3: PAUS statistical results according to lymph node status and patient's age.

\begin{tabular}{|c|c|c|c|c|c|c|c|}
\hline \multicolumn{8}{|c|}{ PAUS Statistical Results According to Lymph Node Status and Patient's Age } \\
\hline \multirow{3}{*}{ Tumor size } & $\mathrm{T} 1$ & $\begin{array}{r}348 \\
(52.2 \%)\end{array}$ & $\begin{array}{r}265 \\
(70.5 \%)\end{array}$ & $\begin{array}{c}47 \\
(42.7 \%)\end{array}$ & $\begin{array}{c}25 \\
(30.1 \%)\end{array}$ & $\begin{array}{c}11 \\
(45.8 \%)\end{array}$ & \multirow{2}{*}{$<0.001$} \\
\hline & $\mathrm{T} 2$ & $\begin{array}{r}245 \\
(36.7 \%)\end{array}$ & $\begin{array}{r}111 \\
(29.5 \%)\end{array}$ & $\begin{array}{r}63 \\
(57.3 \%)\end{array}$ & $\begin{array}{r}58 \\
(69.9 \%)\end{array}$ & $\begin{array}{c}13 \\
(54.2 \%)\end{array}$ & \\
\hline & Unknown & $\begin{array}{c}74 \\
(11.1 \%)\end{array}$ & - & - & - & - & \\
\hline \multirow{3}{*}{ Tumor grade } & G1 & $\begin{array}{r}88 \\
(13.2 \%)\end{array}$ & $\begin{array}{r}64 \\
(72.7 \%)\end{array}$ & $\begin{array}{c}9 \\
(10.2 \%)\end{array}$ & $\begin{array}{r}11 \\
(8.8 \%)\end{array}$ & $\begin{array}{c}4 \\
(4.5 \%)\end{array}$ & \multirow{3}{*}{0.034} \\
\hline & G2 & $\begin{array}{r}425 \\
(63.7 \%)\end{array}$ & $\begin{array}{r}267 \\
(62.8 \%)\end{array}$ & $\begin{array}{c}80 \\
(18.8 \%)\end{array}$ & $\begin{array}{c}64 \\
(15.1 \%)\end{array}$ & $\begin{array}{r}14 \\
(3.3 \%)\end{array}$ & \\
\hline & G3 & $\begin{array}{r}154 \\
(23.1 \%)\end{array}$ & $\begin{array}{c}79 \\
(51.3 \%)\end{array}$ & $\begin{array}{r}36 \\
(23.4 \%)\end{array}$ & $\begin{array}{c}30 \\
(19.5 \%)\end{array}$ & $\begin{array}{c}9 \\
(5.8 \%)\end{array}$ & \\
\hline \multirow{3}{*}{ ER status } & Positive & $289(43.3 \%)$ & $184(65.7 \%)$ & $50(64.1 \%)$ & $42(51.2 \%)$ & $13(65.0 \%)$ & \multirow{2}{*}{0.12} \\
\hline & Negative & $171(25.6 \%)$ & $96(34.3 \%)$ & $28(35.9 \%)$ & $40(48.8 \%)$ & $7(35.0 \%)$ & \\
\hline & Unknown & $207(31.0 \%)$ & - & - & - & - & \\
\hline \multirow{3}{*}{ PR status } & Positive & $162(24.3 \%)$ & $105(37.6 \%)$ & $32(40.5 \%)$ & $17(20.7 \%)$ & $8(40.0 \%)$ & \multirow{2}{*}{0.024} \\
\hline & Negative & $298(44.7 \%)$ & $174(62.4 \%)$ & 47 (59.5\%) & $65(79.3 \%)$ & $12(60.0 \%)$ & \\
\hline & Unknown & 207 (31.0\%) & - & - & - & - & \\
\hline \multirow{3}{*}{ HER2 status } & Positive & $79(11.8 \%)$ & $43(15.5 \%)$ & $15(18.8 \%)$ & $20(24.4 \%)$ & $1(5.0 \%)$ & \multirow{2}{*}{0.125} \\
\hline & Negative & $380(57.0 \%)$ & $234(84.5 \%)$ & $65(81.3 \%)$ & $62(75.6 \%)$ & $19(95.0 \%)$ & \\
\hline & Unknown & 208 (31.2\%) & - & - & - & - & \\
\hline
\end{tabular}




\begin{tabular}{|c|c|c|c|c|c|c|c|}
\hline \multirow{3}{*}{$\begin{array}{c}\text { Vascular } \\
\text { spread }\end{array}$} & Positive & $241(36.2 \%)$ & $89(23.5 \%)$ & $65(54.6 \%)$ & 75 (77.3\%) & $12(48.0 \%)$ & \multirow[b]{2}{*}{$<0.001$} \\
\hline & Negative & $379(56.8 \%)$ & $290(76.5 \%)$ & $54(45.4 \%)$ & $22(22.7 \%)$ & $13(52.0 \%)$ & \\
\hline & Unknown & $47(7 \%)$ & - & - & - & - & \\
\hline \multirow{3}{*}{$\begin{array}{l}\text { Lymphat- } \\
\quad \text { ic } \\
\text { spread }\end{array}$} & Positive & $331(49.6 \%)$ & $112(29.6 \%)$ & $116(98.3 \%)$ & 95 (97.9\%) & $8(32.0 \%)$ & \multirow{2}{*}{$<0.001$} \\
\hline & Negative & $\begin{array}{c}288 \\
(43.2 \%) \\
\end{array}$ & $\begin{array}{c}267 \\
(70.4 \%) \\
\end{array}$ & $\begin{array}{c}2 \\
(1.7 \%) \\
\end{array}$ & $\begin{array}{c}2 \\
(2.1 \%) \\
\end{array}$ & $\begin{array}{c}17 \\
(68.0 \%)\end{array}$ & \\
\hline & Unknown & $\begin{array}{l}48 \\
\quad(7.2 \%) \\
\end{array}$ & - & - & - & - & \\
\hline \multirow{3}{*}{$\begin{array}{l}\text { Nodal } \\
\text { status }\end{array}$} & pN0 & $\begin{array}{c}437 \\
(65.5 \%)\end{array}$ & 410 & - & - & 27 & \multirow{3}{*}{$<0.001$} \\
\hline & pN1 & $\begin{array}{l}189 \\
(28.4 \%)\end{array}$ & - & 110 & 79 & - & \\
\hline & pN2 & $41(6.1 \%)$ & - & 15 & 26 & - & \\
\hline Total & & $667(100 \%)$ & $410(61.5 \%)$ & $125(18.7 \%)$ & $105(15.7 \%)$ & $\begin{array}{l}27 \\
\quad(4.1)\end{array}$ & \\
\hline
\end{tabular}

In younger patients, false-negative PAUS results (10.4\%) were more frequently found than true-negative $(2.7 \%)(p=0.006)$. In cases when the tumor size was larger (T2), false-negative (57.3\%) and true-positive (69.9\%) results of the study were more often detected $(\mathrm{p}<0.0001)$, in contrast to cases when the Tumor Size was smaller (T1), when true-negative $(70.5 \%)$ results were more often detected. Statistically significantly more frequent false-negative results of ultrasound examination were obtained in cases with poorly-differentiated tumors (G3), in $23.4 \%$ of cases ( $\mathrm{p}=0.034$ ). In cases with tumor spreading in blood vessels and lymphatic vessels, false-negative and true-positive PAUS results were higher (V1 54.6\% and 77.3\%, L1 98.3\% and 97.9\%), otherwise true-negative PAUS results were lower (V1 - 23.5\%, L1 - 29.6\%) ( $\mathrm{p}<0.0001)$. Expression of the estrogen (ER), progestin (PR) and human epidermal growth factor (HER2)) was not statistically significant for PAUS results (Table 2). After surgery in PAUS-positive cases, heavy nodal disease burden $(\mathrm{pN} 2)$, larger tumor $(\mathrm{T} 2)(\mathrm{p}<0.0001)$, and poorly-differentiated tumors (G3) ( $p=0.034)$ were more frequently found and tumor spreading in the blood and Lymphatic Vessels (LV1) was more often detected $(\mathrm{p}<0.0001)$ (Table 2$)$.

\section{Discussion}

According to the literature, metastatic lymph nodes are detected in about $30-40 \%$ cases of newly diagnosed breast cancer [18]. In order to evaluate the status of axillary lymph nodes, all patients undergo surgical intervention (SLNB or ALND) to this day. Although SLNB is less risky than ALND, about $60-70 \%$ cases of newly diagnosed breast cancer are node-negative and axillary surgical intervention is unnecessary. In our study, metastatic lymph nodes were detected in 230 patients (34.5\%), but in all 667 cases, either SLNB or primary ALND, or SLNB and secondary ALND were performed; however, for 437 patients (65.5\%), axillary surgical interventions were unnecessary. In the guidelines of the European Union, PAUS is a routine examination for all breast cancer patients with palpable or impalpable axillary lymph nodes [4]. Recently, if there is definitely pathological axillary lymph nodes by ultrasound examination, neoadjuvant chemotherapy has been initiated. During the study period, our clinic had two possible solutions: either primary ALND or neoadjuvant chemotherapy; therefore, in 86 cases, primary ALND was performed. Patients with normal-appearing or suspicious lymph nodes on PAUS ( $\mathrm{n}=581)$ underwent SLNB.

According to the ACOSOG Z0011 study [5], after SLNB in 68 cases $(11.7 \%)$ metastases were found in three sentinel lymph nodes and the secondary ALND was performed; however, metastases were found in one or two lymph nodes (pN2) in only 24 (35.3\%) cases, while the additional removed nodes were undamaged in the remaining 44 cases (64.7\%). Other studies [19-22] also found that in about $40-70 \%$ cases of all additional removed lymph nodes metastases were not detected. The question of what is widespread lymph node damage is still asked? According to the ACOSOG Z0011 study, extensive lymph node damage occurs when metastases are found in three or more lymph nodes. However, according to international recommendations, extensive lymph node damage, which requires the additional treatment of the axilla, is when metastases are found in four or more lymph nodes (pN2 according to TNM classification) [23]. One of the goals of our study was to evaluate the reliability of PAUS in detecting metastatic disease in more than three axillary lymph nodes (pN2). For detecting pN2, the accuracy of PAUS was 91.2\% and NPV 96.5\%, with pN1 being $78.1 \%$ and $78.8 \%$, respectively. In the study by Schipper et al., heavy nodal disease burden (pN2- pN3) was found in $4.4 \%$ of the 577 PAUS-negative cases, and NPV was 95.5\% [18]. 
In the study by Abe and others ( $\mathrm{N}=37)$, for the determination of pN2 or pN3, false-negative results of PAUS were found in 3\% cases, and NPV was $96.7 \%$ [8]. Based on these results, it can be argued that the PAUS study is sufficiently precise in detecting a heavy nodal disease burden (pN2) and additional axillary surgery could be avoided in most cases. Perhaps in these cases, a PAUS study could replace the SLNB and these patients could avoid an axillary surgery, meaning that the surgery time would be shorter, and treatment costs and postoperative complications would be reduced. A large number of studies were performed to evaluate the diagnostic parameters of the PAUS: accuracy $67.9 \%$ to $90.2 \%$, sensitivity $23 \%$ to $87 \%$, specificity $76.9 \%$ to $100 \%$, and NPV $60 \%$ to $89.2 \%$ (Table 4 ). In the study by Dihge et al., the sensitivity of PAUS was only $23 \%$ [5], while the study by Tillman et al. reported a sensitivity of $87 \%$ [10]. In our study, the PAUS study in all patients was not very sensitive (45.7\%), but was very specific (93.8\%), sufficiently accurate $(77.2 \%)$ and had relatively high positive and negative predictive values (79.5\% and 76.6\%) (Table 3 ).

Table 4: PAUS statistical results of several studies.

\begin{tabular}{|c|c|c|c|c|c|c|}
\hline Preoperative PAUS & $\begin{array}{c}\text { Prevalence (\%) } \\
\text { 95\% CI }\end{array}$ & $\begin{array}{c}\text { Accuracy (\%) } \\
95 \% \mathrm{CI}\end{array}$ & $\begin{array}{c}\text { Sensitivity } \\
(\%) \\
95 \% \text { CI }\end{array}$ & $\begin{array}{c}\text { Specifisity } \\
\text { (\%) } \\
95 \% \text { CI }\end{array}$ & PPV (\%) 95\% CI & NPV (\%) 95\% CI \\
\hline Total & $\begin{array}{c}35.5 \\
(30.9-38.1)\end{array}$ & $\begin{array}{c}77.2 \\
(74.0-80.4)\end{array}$ & $\begin{array}{c}45.7 \\
(39.2-52.1)\end{array}$ & $\begin{array}{c}93.8 \\
(91.6-96.1)\end{array}$ & $\begin{array}{c}79.5 \\
(72.7-86.4)\end{array}$ & $\begin{array}{c}76.6 \\
(73.0-80.2)\end{array}$ \\
\hline pN1 & $\begin{array}{c}30.2 \\
(26.6-33.8)\end{array}$ & $\begin{array}{c}78.1 \\
(74.9-81.4)\end{array}$ & $\begin{array}{r}41.8 \\
(34.8-8.8)\end{array}$ & $\begin{array}{c}93.8 \\
(91.6-96.1)\end{array}$ & $\begin{array}{c}74.5 \\
(66.2-82.8)\end{array}$ & $\begin{array}{c}78.8 \\
(75.3-82.4)\end{array}$ \\
\hline $\mathrm{pN} 2$ & $\begin{array}{c}8.6 \\
(6.1-11.1)\end{array}$ & $\begin{array}{c}91.2 \\
(88.7-93.8)\end{array}$ & $\begin{array}{c}63.4 \\
(48.7-78.2)\end{array}$ & $\begin{array}{c}93.8 \\
(91.6-96.1)\end{array}$ & $\begin{array}{c}49.1 \\
(35.6-62.5)\end{array}$ & $\begin{array}{c}96.5 \\
(94.7-98.2)\end{array}$ \\
\hline $\begin{array}{l}<40 \text { years } \\
(\mathrm{N}=30)\end{array}$ & $\begin{array}{c}60.0 \\
(42.5-77.5)\end{array}$ & $\begin{array}{c}53.3 \\
(35.5-71.2)\end{array}$ & $\begin{array}{c}27.8 \\
(7.1-48.5)\end{array}$ & $\begin{array}{c}91.7 \\
(76.0-107.3)\end{array}$ & $\begin{array}{c}83.3 \\
(53.5-113.2)\end{array}$ & $\begin{array}{c}45.8 \\
(25.9-65.8)\end{array}$ \\
\hline $\begin{array}{l}40-69 \text { years } \\
(\mathrm{N}=476)\end{array}$ & $\begin{array}{c}33.4 \\
(29.2-37.6)\end{array}$ & $\begin{array}{c}78.8 \\
(75.1-82.5)\end{array}$ & $\begin{array}{c}45.9 \\
(38.2-53.7)\end{array}$ & $\begin{array}{c}95.3 \\
(92.9-97.6)\end{array}$ & $\begin{array}{c}83.0 \\
(75.1-90.8)\end{array}$ & $\begin{array}{c}77.8 \\
(73.7-82.0)\end{array}$ \\
\hline $\begin{array}{l}>=70 \text { years } \\
(\mathrm{N}=161)\end{array}$ & $\begin{array}{c}32.9 \\
(25.7-40.2)\end{array}$ & $\begin{array}{c}77.0 \\
(70.5-83.5)\end{array}$ & $\begin{array}{c}50.9 \\
(37.5-64.4)\end{array}$ & $\begin{array}{c}89.8 \\
(84.1-95.5)\end{array}$ & $\begin{array}{c}71.1 \\
(56.6-85.5)\end{array}$ & $\begin{array}{c}78.9 \\
(71.6-86.1)\end{array}$ \\
\hline
\end{tabular}

(PAUS: preoperative axillary lymph node; PPV: positive prognostic value; NPV: negative prognostic value)

Most often, metastases were found in young women (60\%), but the accuracy of PAUS was the lowest (53.3\%), while metastases were found less often in the axillary lymph nodes in middle-aged and older women $(33.4 \%$ and $32.9 \%)$, and the PAUS study was quite accurate $(78.8 \%$ and $77.0 \%)$. These results suggest that the PAUS study can be more reliable for middle-aged and elderly women, but should be considered more cautiously when it is performed in young women (Table 3). Few studies have been conducted to analyze the causes of false-negative results of an ultrasound examination. Jalin's study suggests that the negative results of PAUS study should be evaluated with caution when the tumor is larger ( $\geq \mathrm{T} 2)$, poorly differentiated (G3), or when tumor spreading in blood vessels and lymphatic vessels is detected, as that increases the probability of false-negative results [3]. Nwaugu's study also suggests that the probability of false-negative outcomes increases when the tumor is larger and the tumor spreading in blood vessels and lymph nodes is diagnosed, but the tumor differentiation degree is not statistically significant [15]. In our study, false-negative PAUS results were found in $18.7 \%$ of cases (Table 5).

Table 5.

\begin{tabular}{|c|c|c|c|c|c|c|c|}
\hline & & Examination & Accuracy (\%) & Sensitivity (\%) & Specifisity (\%) & PPV (\%) & NPV (\%) \\
\hline \multirow{2}{*}{2} & H Abe et al. & US (Total) & 72.1 & 56.3 & 80.8 & 61.9 & 77 \\
\cline { 2 - 8 } & {$[8]$} & US (N1) & 70.7 & 44.6 & 80.8 & 47.3 & 79.1 \\
\hline \multirow{2}{*}{3} & TPJ Farrell et & US & - & 64 & 76.9 & 63.8 & 77.1 \\
\cline { 2 - 8 } & al. [9] & US+FNA & - & 86.2 & 100 & 71.9 \\
\multirow{2}{*}{4} & RH Tillman & US & - & 87 & 98 & - \\
\cline { 2 - 8 } & & US+CNB & - & 90 & 100 & - \\
\hline
\end{tabular}




\begin{tabular}{|c|c|c|c|c|c|c|c|}
\hline 6 & $\begin{array}{l}\text { B Lee et al. } \\
\text { [11] }\end{array}$ & US & 67.9 & 53.7 & 85.1 & 81 & 60 \\
\hline \multirow{2}{*}{7} & \multirow{2}{*}{$\begin{array}{c}\text { L Dihge et al. } \\
\text { [5] }\end{array}$} & US & 68.3 & 23 & 95 & 73 & 68 \\
\hline & & US+FNA & 80 & 73 & 100 & 100 & 57 \\
\hline \multirow{3}{*}{10} & \multirow{3}{*}{ TJA Nijnatten et al. [12] } & US (Total) & 90.2 & 47.1 & 100 & 100 & 89.2 \\
\hline & & US (N1) & 91.1 & 40.7 & 100 & 100 & 90.6 \\
\hline & & US (N2) & 98.5 & 68.8 & 100 & 100 & 98.4 \\
\hline \multirow{2}{*}{11} & \multirow{2}{*}{$\begin{array}{c}\text { I Barco et al. } \\
\text { [6] }\end{array}$} & US & - & 47.5 & 93.6 & 82.5 & 73.8 \\
\hline & & US+FNA & - & 80 & 100 & 100 & - \\
\hline 13 & $\begin{array}{c}\text { Ch Berckelaer et } \\
\text { al. [13] }\end{array}$ & US+FNA & 92 & 75 & 100 & - & - \\
\hline \multirow{2}{*}{15} & \multirow{2}{*}{$\begin{array}{l}\text { J Cools Lartigue } \\
\text { [14] }\end{array}$} & US & - & 55 & 88 & - & - \\
\hline & & US+FNA & 70 & 69 & 100 & 100 & 54 \\
\hline 16 & $\begin{array}{l}\text { IY Nwaogu et } \\
\text { al. [15] }\end{array}$ & US & 79 & - & - & - & - \\
\hline \multirow{2}{*}{18} & \multirow{2}{*}{$\begin{array}{l}\text { RS Jackson et } \\
\text { al. [2] }\end{array}$} & US (Total) & - & 45 & 85 & 51 & 82 \\
\hline & & US ( $>=3 \mathrm{mts}$ ) & - & 71 & 83 & 31 & 86 \\
\hline \multirow{2}{*}{20} & \multirow{2}{*}{$\begin{array}{c}\text { Y Feng et al. } \\
{[16]}\end{array}$} & US & 76.7 & 58.6 & 89.4 & 79.6 & 75.3 \\
\hline & & US+FNA & 80.3 & 52.4 & 100 & 100 & 74.8 \\
\hline 22 & D Black [17] & US+FNA & - & 86.4 & 100 & - & 67 \\
\hline 23 & $\begin{array}{c}\text { RJ Schipper et } \\
\text { al. [12] }\end{array}$ & US & 78.7 & 47.6 & 95.7 & 86.9 & 77 \\
\hline \multirow{2}{*}{24} & \multirow[t]{2}{*}{ NS Tucker } & US & 85.5 & 54.3 & 100 & 100 & 82.5 \\
\hline & & US+FNA & 82.2 & 44.1 & 100 & 100 & 79.4 \\
\hline \multirow{3}{*}{25} & \multirow{3}{*}{ D. Artmoniene } & US (Total) & 77.2 & 45.7 & 93.8 & 79.5 & 76.6 \\
\hline & & US (N1) & 78.1 & 41.8 & 93.8 & 74.5 & 78.8 \\
\hline & & US (N2) & 91.2 & 63.4 & 93.8 & 49.1 & 96.5 \\
\hline
\end{tabular}

(US: Ultrasound; CNB: Core Needle Biopsy; FNA: Fine Needle Aspiration; PPV: Positive Predictive Value; NPV: Negative Predictive Value)

In the young age group, the false-negative results of the PAUS study were statistically significantly more frequent $(10.4 \%)$ than the true-negative $(2.7 \%)(\mathrm{p}=0.006)$, and there were no statistically significant differences in other age groups. In our study, in the case of a larger tumor (T2), false-negative (57.3\%) and true-positive (69.9\%) PAUS results were statistically significantly more frequent $(\mathrm{p}<0.0001)$; in the case of smaller tumors (T1), true- negative study results were more often received (70.5\%). Also, false-negative results of the PAUS study were found statistically significantly more frequently ( $p=0.034)$ in poorly-differentiated tumors (G3) $(23.4 \%)$ than in well-differentiated tumors (G1) (10.2\%). In the presence of tumor spreading in blood vessels and lymphatic vessels, false-neg- ative and true-positive PAUS study results were statistically significantly $(\mathrm{p}<0.0001)$ more frequent (V1 $-54.6 \%$ and $77.3 \%$, L1 - 98.3\% and 97.9\%) than true-negative results (V1 - 23.5\%, L1 29.6\%). ER, PR and HER2 expression were not statistically significant for PAUS study results.

In assessing these results, it can be argued that in the middle-aged and elderly patients, when the tumor is small (T1), well-differentiated (G1) and tumor spreading in Blood Vessels (V0) and Lymphatic Vessels (L0) is not detected, we could rely on PAUS study results and avoid SLNB. On the contrary, in the younger age group with a larger (T2), poorly-differentiated (G3) tumor, and the 
detection of tumor spreading in Blood Vessels (V1) and Lymphatic Vessels (L1), the probability of false-negative results is increased; therefore, in these cases, the results of the PAUS study should be evaluated more cautiously. Several studies identified that a heavy nodal disease burden (pN2) and worse prognostic factors of disease (T2, G3, VL1) were detected more frequently in the PAUS-positive group [1,3-5,7,22,24]. Also in our study, in the PAUS-positive group after surgery, a heavy nodal disease burden (pN2) and worse prognostic factors of disease (T2 $(\mathrm{p}<0.0001), \mathrm{G} 3(\mathrm{p}=0.034), \mathrm{LV} 1$ $(p<0.0001)$ ) were detected more frequently. These results indicate that when pathological or suspicious axillary lymph nodes are found by PAUS, there is a higher possibility that the tumor will be more aggressive and more widespread, so these patients require more aggressive treatment of the axillary lymph nodes (operational or radiotherapy).

\section{Conclusion}

An ultrasound examination is sufficiently accurate to detect a heavy nodal disease burden (pN2) and an additional axillary surgery can be avoided in most cases. Ultrasound examination is more accurate and more sensitive to middle-aged and older women and the sensitivity of the young women's ultrasound examination is rather low. In the middle-aged and elderly patients, when the tumor is small (T1), well-differentiated (G1) and the tumor spreading in blood vessels (V0) and lymphatic vessels (LO) is not detected, we can rely on PAUS study results and avoid SLNB. On the contrary, in the younger age group with larger (T2), poorly-differentiated (G3) tumors, and with the detection of tumor spreading in blood vessels (V1) and lymphatic vessels (L1), the probability of false-negative results is increased. Therefore, in these cases, the results of the PAUS study should be evaluated more cautiously. In PAUS-positive patients there is a greater possibility that the tumor will be more aggressive and more widespread, so these patients require more aggressive treatment of the axillary lymph nodes (operational or radiotherapy).

\section{References}

1. Boone BA, Huynh C, Spangler ML, Sumkin J, Johnson R, et al. (2015) Axillary lymph node burden in invasive breast cancer: a comparison of the predictive value of ultrasound-guided needle biopsy and sentinel lymph node biopsy. Clin Breast Cancer 15(5): 243-248.

2. Jackson RS, Mylander Ch, Rosman M, Andrade R, Sawyer K, et al. (2015) Normal axillary ultrasound excludes heavy nodal disease burden in patients with breast cancer. Ann Surg Oncol 22(10): 3289-3295.

3. Jalini L, Fung DFN, Dasgupta KK, Kurup V (2016) Clinicopathological factors associted with positive preoperative axillary ultrasound scanning in breast cancer patients. Intern J Surg Med 2(1): 23-29.

4. Verheuvel NC, Hoven I, Ooms HWA, Voogd AC, Roumen RMH (2015) The role of ultrasound- guided lymph node biopsy in axillary staging of invasive breast cancer in the post-ACOSOG Z0011 trial era. Ann Surg Oncol 22(2): 409-415.

5. Dihge L, Grabau DA, Rasmussen RW, Bendahl PO, Ryden L (2016) The accuracy of preoperative axillary nodal staging in primary breast cancer by ultrasound is modified by nodal metastatic load and tumor biology. Acta Oncologica 55(8): 976-982.

6. Barco I, Chabrera C, Garcia FA, Fraile M, Gonzalez S, et al. (2016) Role fo axillary ultrasound, magnetic resonance imaging, and ultrasound- guided fine-needle aspiration biopsy in the preoperative triage of breast cancer patients. Clin Transl Oncol 19(6): 704-710.

7. Gipponi M, Fregatti P, Garlaschi A, Murelli F, Margarino C, et al. (2016) Axillary ultrasound and fine-needle aspiration cytology in the preoperative staging of axillary node metastasis in breast cancer patients. Breast 30: 146-150.

8. Abe H, Schach D, Sennett ChA, Newstead GM, Schmidt RA (2013) Utility of preoperative ultrasound for predicting pN2 or higher stage axillary lymph node involvement in patients with newly diagnosed breast cancer. AJR 200(3): 696-702.

9. Farrell TPJ, Adams NC, Stenson M, Carroll PA, Griffin M, et al. (2015) The Z0011 trial: is this the end of axillary ultrasound in the pre-operative assessment of breast cancer patients? Eur Radiol 25(9): 2682-2687.

10. Henry TR, Glover CK, Preston M, Gallagher K, Tummel E, et al. (2015) The save review: Sonographic analysis versus excision for axillary staging in breast cancer. J Am Coll Surg 220(4): 560-567.

11. Lee B, Lim AK, Krell J, Satchithananda K, Coombes RCH, et al. (2013) The efficacy of axillary ultrasound in the detection of nodal metastasis in breast cancer. AJR 200(3): 314- 320.

12. Nijnatten TJA, Ploumen EH, Schipper RJ, Goorts B, Andriessen EH, et al. (2016) Routine use of standart breast MRI compared to axillary ultrasound for differentiating between no, limited and advanced axillary nodal disease in newly diagnosed breast cancer patients. Eur J Radiol 85(12): 2288- 2294.

13. Berckelaer Ch, Huizing M, Goethem M, Vervaecke A, Papadimitriou $\mathrm{K}$, et al. (2016) Preoperative ultrasound staging of the axilla make's preoperative examination of the sentinel node redundant in breast cancer: Saving tissue, time and money. Eur J Obst Gyn Reprod Biol 206: 164-171.

14. Cools LJ, Sinclair A, Trabulsi N, Meguerditchian A, Mesurolle B, et al. (2013) Preoperative axillary ultrasound and fine-needle aspiration biopsy in the diagnosis of axillary metastases in patients with breast cancer: predictors of accuracy and future implications. Ann Surg Oncol 20(3): 819-827.

15. Nwaogu IY, Yan Y, Appleton CM, Cyr AE, Margenthaler JA (2015) Predictors of false negative axillary ultrasound in breast cancer. J. Surg. Research 198(2): 351-354.

16. Feng Y, Huang R, He Y, Lu A, Fan Z, et al. (2015) Efficacy of physical examination, ultrasound, and ultrasound combined with fine-needle aspiration for axilla staging of primary breast cancer. Breast cancer Res Treat 149(3): 761-765.

17. Black D (2017) Axillary ultrasound:for all, for none, to diagnose positive nodes, or to support avoiding sentinel lymph node biopsy altogether. Ann Surg Oncol 24(1): 64-69.

18. Shipper RJ, Roozendaal LM, Vries B, Pijnappel RM, Beets Tan RGH, et al. (2013) Axillary ultrasound for preoperative nodal staging in breast cancer patients: Is it of added value? Breast 22(6): 1108-1113.

19. Gur AS, Unal B, Ozbek U, Ozmen V, Aydogan F, et al. (2010) Validation of breast cancer nomograms for predicting the non-sentinel lymph node metastases after a positive sentinel lymph node biopsy in a multi-center study. Eur J Surg Oncol 36(1): 30-35.

20. Coufal O, Pavlik T, Fabian P, Bori R, Boross G, et al. (2009) Predicting non-sentinel lymph node status after positive sentinel biopsy in breast cancer: what model performs the best in a czech population? Patrol Oncol Res15(4): 733-740.

21. Coutant C, Rouzier R, Fondrinier E, Marchal F, Guillemin F, et al. (2009) Validation of the tenon breast cancer score for predicting non-sentinel lymph node status in breast cancer patients with sentinel lymph node metastasis: A prospective multi center study. Breast Cancer Res Treat 113(3): 537-543. 
22. Nath J, Sami N, Massey J, Donnelly J, Corder AP (2013) Selection for axillary clearance in breast cancer (ultrasound negative, sentinel node positive patients have low rates of further metastases. EJSO 39(5): 450454.

23. Verheuvel NC, Ooms HWA, Tjan Heijnen VCG, Roumen RMH, Voogd AC (2016) Predictors for extensive nodal involvement in breast cancer patients with axillary lymph node metastases. Breast 27: 175-181.

ISSN: 2574-1241

DOI: 10.26717/BJSTR.2019.12.002301

Dalia Artmoniene. Biomed J Sci \& Tech Res

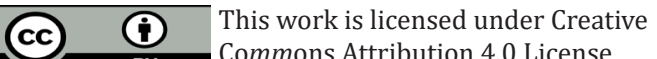

Submission Link: https://biomedres.us/submit-manuscript.php
24.Saffar B, Bennett M, Metcalf C, Burrows S (2015) Retrospective preoperative assessment of the axillary lymph nodes in patients with breast cancer and literature review. Clinical radiology 70(9): 954-959.

$\begin{array}{ll}\text { BIOMEDICAL } & \text { Assets of Publishing with us } \\ \text { RESEARCHES } & \text { - Global archiving of articles } \\ & \text { - Immediate, unrestricted online access } \\ & \text { - Rigorous Peer Review Process } \\ & \text { - Authors Retain Copyrights } \\ \end{array}$

